\title{
A Validated RP-HPLC Method for Simultaneous Estimation of Antidiabetic Drugs Pioglitazone HCl and Glimepiride
}

\author{
Khohinur Hossain", Asma Rahman², Md. Zakir Sultan², Farhana Islam³ , Md. Akteruzzaman', \\ Md. Abdus Salam ${ }^{1}$ and Mohammad A. Rashid ${ }^{3}$ \\ ${ }^{1}$ Department of Chemistry, University of Dhaka, Dhaka-1000, Bangladesh. \\ ${ }^{2}$ Centre for Advanced Research in Sciences (CARS), University of Dhaka, Dhaka-1000, Bangladesh. \\ ${ }^{3}$ Department of Pharmaceutical Chemistry, Faculty of Pharmacy, University of Dhaka, Dhaka-1000, Bangladesh
}

\begin{abstract}
A simple, fast and economic reversed phase high performance liquid chromatographic (RP-HPLC) method has been developed and validated for simultaneous and quantitative analyses of pioglitazone $\mathrm{HCl}$ and glimepiride in pharmaceutical dosage forms. The method was developed using the mobile phase comprising of potassium dihydrogen phosphate buffer $\left(\mathrm{KH}_{2} \mathrm{PO}_{4}\right)$ at $\mathrm{pH} 3.4$ and acetonitrile in the ratio of 40:60 (v/v) over C-18 bonded silica column ( 250 x $4.6 \mathrm{~mm}, 5 \mathrm{um}$, Phenomenex Inc.) at ambient temperature. The flow rate was at $0.8 \mathrm{~min} / \mathrm{min}$ and the eluent was monitored by UV detection at $235 \mathrm{~nm}$. The recoveries were found to be $>97 \%$ for pioglitazone and $>99 \%$ for glimepiride, demonstrative of accuracy of the protocol. Inter-day and intra-day precision of the new method were less than the maximum allowable limit (RSD\% $\leq 2.0)$ according to ICH, USP and FDA guidelines. The method showed linear response with correlation coefficient $\left(\mathrm{r}^{2}\right)$ values of 0.9991 for pioglitazone and 0.9999 for glimepiride. Therefore, the method was found to be accurate, reproducible, sensitive and less time consuming and can be successfully applied for the assay of pioglitazone and glimepiride in combined formulations.
\end{abstract}

Key words: Antidiabetic, pioglitazone, glimepiride, reversed phase, HPLC, method validation

\section{Introduction}

Pioglitazone is an oral anti-hyperglycemic drug of the thiazolidinedione class. Chemically it is (RS)-5-(4-[2-(5ethylpyridin-2-yl)ethoxy]benzyl)thiazolidine-2,4-dione (Figure 1A). It acts by decreasing insulin resistance. It is used in the treatment of type-II diabetes mellitus (Gillies and Dunn, 2000; Smith, 2001; Belfort et al., 2006; DeFronzo et al., 2011). Glimepiride is also an oral antihperglycemic drug belongs to sulfonylurea group. It is 3-ethyl-4-methyl- $N$-(4-[N-((1r,4r)-4-methylcyclohexylcarbamoyl) sulfamoyl]phenethyl)-2-oxo-2,5-dihydro- $1 H$ pyrrole-1-carboxamide (Figure 1B) and is effective at low doses in patients with non-insulin-dependent diabetes mellitus (Langtry and Balfour, 1998; Rosenkranz et al., 1996; Müller et al., 1995).

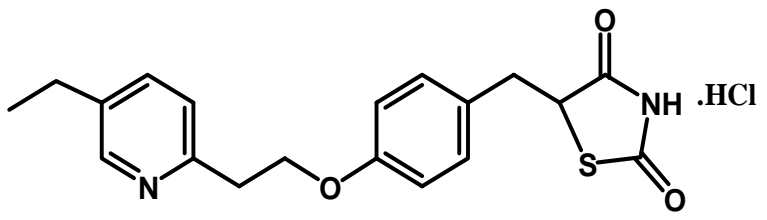

A

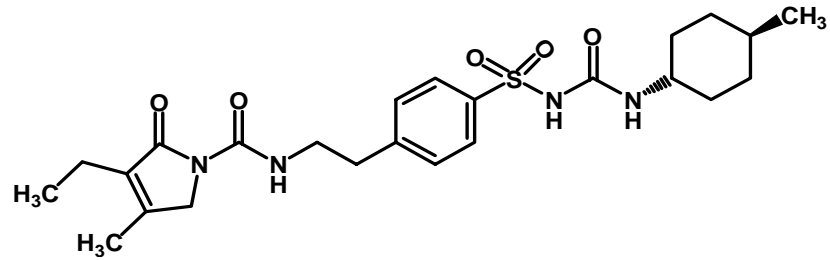

B

Figure 1. Structures of pioglitazone hydrochloride (A) and glimepride (B).

Drug requires some absolute necessities like quality, potency etc. to exhibit its best activities. It is obvious that a little change in the formulation or variations in the manufacturing process or use of low quality materials can affect the product stability and efficacy. Use of low quality or adulterated drug introduces more toxins in the body. It can be harmful to the patient to a high risk level. Quality and efficacy assessments and maintenance of proper dosage schedule are strongly emphasized to ensure their safety and efficacy. Therefore, these drugs required a

Correspondence to: Mohammad A. Rashid, Department of Pharmaceutical Chemistry, Faculty of Pharmacy, University of Dhaka, Dhaka-1000, Bangladesh. Tel.: +88-02-9661900-73, Extn.- 8137. Fax: +88-02-8615583; E-mail: rashidma@du.ac.bd 
simple, rapid and accurate method for simultaneous and routine analysis.

The literature survey reveals several analytical methods for quantitative estimation of pioglitazone hydrochloride and glimepride in pharmaceutical formulations and in body fluids. These methods include high performance liquid chromatography [HPLC] for pioglitazone hydrochloride, glimepride and for both in other combinations (Sane et al., 2004; Mamdouh et al., 2012; Kalyankar et al., 2010; Ramesh et al., 2010; Lakshmi et al., 2009; Karthik et al., 2008; Navaneethan et al., 2011). The present work was aimed to develop a simple, rapid and accurate RP-HPLC method for the simultaneous quantification of pioglitazone hydrochloride and glimepride in bulk form or in their pharmaceutical formulations and to validate the method according to ICH and FDA guidelines with respect to the parameters of accuracy, precision, linearity and specificity (Sultan et al., 2012; Sultan, et al., 2011(a, b); FDA, 2012; ICH (Q2A and Q2B); USP, 2009).

\section{Materials and Methods}

Drugs and Materials: Working standard of pioglitazone $\mathrm{HCl}$ (potency 99.95\%) and glimepiride (potency 99.99\%) were kind gift of Drug International Ltd., Dhaka, Bangladesh. For the estimation of pioglitazone and glimepiride formulated as tablets, samples produced by renowned pharmaceutical industries of Bangladesh were collected from the market. HPLC grade acetonitrile and methanol were procured from Active Fine Chemicals Ltd., Dhaka Bangladesh.

\section{Instrumentation}

HPLC system: High Performance Liquid Chromatography system (Shimadzu-UFLC Prominence), equipped with an auto sampler (Model-SIL 20AC HT) and UV-Visible detector (Model-SPD 20A) was used for the analysis. The data was recorded with LC-solutions software.

Column: An analytical reversed phase C-18 (ODS) column [(4.6 mm x $250 \mathrm{~mm} ; 5 \mu \mathrm{m})$, Phenomenex, Inc] was used to analyze the samples.

Preparation of mobile phase: To prepare buffer solution of $\mathrm{pH}$ 3.4, sodium dihydrogen phosphate $\left(\mathrm{NaH}_{2} \mathrm{PO}_{4}\right)$ (195.5 mg) was taken in a $1000 \mathrm{~mL}$ volumetric flask. About $500 \mathrm{ml}$ of double distilled water was added into the flask, dissolved the salt and finally water was added up to the mark. Then $\mathrm{pH}$ was adjusted to 3.4 by adding dilute phosphoric acid, sonicated for 10 minutes and then filtered through a $0.22 \mu \mathrm{m}$ millipore filter. HPLC grade actonitrile was also filtered and degassed before use into the HPLC system.

Preparation of standard solution: Standard solution of the pure drug was prepared by dissolving $49.062 \mathrm{mg}$ of glimepiride (MW of glimepiride $=490.617$, and potency $=$ 99.99\%) powder equivalent to $100 \mu$ mole glimepiride in a $100 \mathrm{ml}$ volumetric flask using mixture of methanol/acetronitrile (50:50) and $39.290 \mathrm{mg}$ of poiglitazone $\mathrm{HCl}$ (MW of poiglitazone $\mathrm{HCl}=392.90$, and potency $=99.95 \%$ ) powder equivalent to $100 \mu$ mole poiglitazone in $100 \mathrm{ml}$ volumetric flask using methanol as mobile phase. The final concentrations of both solutions were obtained $1 \mu \mathrm{mole} / \mathrm{ml}$. Appropriate from these solution were further diluted to get standards of varying concentrations $(0.5,0.25,0.125,0.0625$ and 0.03125 $\mu \mathrm{mole} / \mathrm{mL})$.

Preparation of test samples: Ten tablets were weighed, made into fine powder in a mortar with pestle and average weight was taken. Accurately weighed powder equivalent to average weight of each tablet (5 $\mu$ mole of pioglitazone and $0.5339 \mu$ mole of glimepiride) were taken in a $50 \mathrm{ml}$ volumetric flask and $10 \mathrm{ml}$ of HPLC-grade methanol/acetronitrile (50:50) mixture was added and sonicated to mix uniformly. The final volume was adjusted with mobile phase to get the concentration of $0.1 \mu \mathrm{mole} / \mathrm{ml}$ for pioglitazone and $0.107 \mu \mathrm{mole} / \mathrm{ml}$ for glimepiride. Then both solutions were further diluted to get the concentrations of $0.05 \mu \mathrm{mole} / \mathrm{ml}$ for pioglitazone and $0.00535 \mu \mathrm{mole} / \mathrm{ml}$ for glimepiride, which were further diluted to get the concentrations of $0.025 \mu \mathrm{mole} / \mathrm{mL}$ for pioglitazone and $0.00265 \mu \mathrm{mole} / \mathrm{ml}$ for glimepiride.

Chromatographic conditions: All analyses were done at ambient temperature under isocratic conditions. The mobile phase contained potasium dihydrogen phosphate buffer $\left(\mathrm{KH}_{2} \mathrm{PO}_{4}\right)$ at $\mathrm{pH} 3.4$ and acetonitrile in the ratio of $40: 60(\mathrm{v} / \mathrm{v})$ at the flow rate $0.8 \mathrm{ml} / \mathrm{min}$. The injection volume was kept at $20 \mu \mathrm{L}$ for all analyses. Before analysis, every standard and sample was filtered through $0.45 \mu \mathrm{m}$ filter tips. The column eluate was monitored at $235 \mathrm{~nm}$. 


\section{Method Validation}

Specificity: The specificity of the HPLC method was evaluated to ensure that there was no interference from the excipients present in the pharmaceutical formulation. The specificity was studied by injecting the excipients, standard solution and pharmaceutical preparation of pioglitazone and glimepiride.

Accuracy: The accuracy of an analytical method expresses the nearest between the expected value and the value obtained. It is expressed by calculating the percent recovery ( $\mathrm{R} \%$ ) of analyte recovered by assay of spiked samples. In this case, aliquot equivalent to $0.0125,0.02$ and $0.05 \mu \mathrm{mole} / \mathrm{mL}$ of standard solutions were analyzed.

Precision: Precision of the assay was investigated with respect to both repeatability and reproducibility. The precision of an analytical method is the degree of agreement among individuals test result where the method is applied repeatedly to multiple samplings. It was checked by intra- and inter-day repeatability of responses after replicate injections and expressed as RSD\%. The calculation formula for RSD\% = (Standard deviation of recovered conc. /Mean recovered conc.) x $100 \%$. In the current method development and validation process, precision was determined by three replicate analyses of each of three concentrations levels of $0.0125,0.025$ and $0.05 \mu \mathrm{mole} / \mathrm{mL}$ of standard solutions using the proposed method.
Linearity: Five different concentration levels 0.5, $0.25,0.125,0.0625$ and $0.03125 \mu \mathrm{mole} / \mathrm{ml}$ were prepared from standard solution of pioglitazone and glimepiride. Then $20 \mu \mathrm{l}$ of each solution was injected thrice times into the HPLC using auto-sampler and the analyses were monitored at $235 \mathrm{~nm}$. The average peak areas were plotted against concentrations. The linearity of the proposed method was determined by using calibration curves to calculate coefficient of correlation, slope and intercept values by using the following equation, $\mathrm{y}=\mathrm{mx}+\mathrm{c}$; where, $y$ is the peak area, $\mathrm{x}$ is the concentration of drug, $\mathrm{m}$ is the slope and c is the intercept.

Robustness: The robustness of the method was studied by minor but deliberate changes in the method like mobile phase composition, $\mathrm{pH}$, buffer, flow rate, detection wavelength, etc.

\section{Results and Discussion}

The reversed phase HPLC method has been developed and validated as per ICH, USP and FDA guide-lines for determination of pioglitazone HCL and glimepiride in pharmaceutical formulations by using the mobile phase comprising potasium dihydrogen phosphate buffer and acetonitrile in the ratio of 40: $60(\mathrm{v} / \mathrm{v})$ at ambient temperature at a flow rate of $0.8 \mathrm{ml} / \mathrm{min}$ with UV detection at $235 \mathrm{~nm}$. The retention time of pioglitazone and glimepiride was obtained at $4.5 \pm 0.1 \mathrm{~min}$ and $10.0 \pm 0.1$ min, respectively (Figure 2).

\section{Chromatogram}

$\mathrm{mV}$

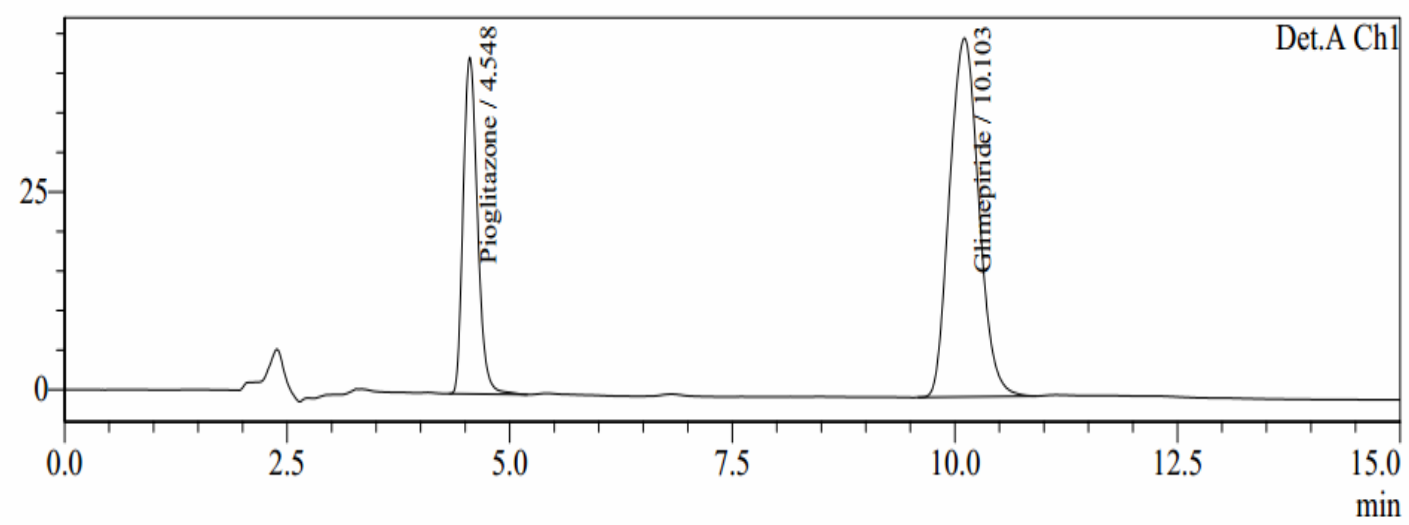

1 Det.A Ch1 $/ 235 \mathrm{~nm}$

Figure 2. HPLC chromatogram of standard pioglitazone and glimepiride. 
The specificity of the method was monitored by analyzing the placebo (containing all the ingredients of the formulation except the analyte), standard solution and market preparation containing pioglitazone and glimepiride. No peak was detected close to the retention time of pioglitazone and glimepiride at the wavelength of detection and hence proved high degree of specificity of the method.

When peak areas (y) were plotted against concentration levels of $0.5,0.25,0.125,0.0625$ and
$0.03125 \mu \mathrm{mole} / \mathrm{ml}$ of standard solutions of pioglitazone and glimepiride, good correlation coefficients were obtained. The correlation coefficients $\left(\mathrm{r}^{2}\right)$ were obtained as 0.9991 for pioglitazone and 0.9999 for glimepiride which were within the acceptable range of guidelines and showed good linearity of the newly developed method. The slope (m) and intercept (c) of the calibration curves were found as 13778153.51 and 92515 for pioglitazone; and 30929176.22 and 124761 for glimipiride. (Table 1, Figure 3)

Table 1. Linearity of the method.

\begin{tabular}{|c|c|c|c|c|c|}
\hline Drug & $\begin{array}{c}\text { Injected conc. } \\
(\mu \mathrm{mole} / \mathrm{mL})\end{array}$ & Mean area $(n=3)$ & Intercept (c) & Slope (m) & $\begin{array}{c}\text { Correlation } \\
\text { coefficient }\left(\mathrm{r}^{2}\right)\end{array}$ \\
\hline \multirow[t]{5}{*}{ Pioglitazone } & 0.03125 & 475864 & \multirow{5}{*}{92515} & \multirow{5}{*}{13778153.51} & \multirow{5}{*}{0.9991} \\
\hline & 0.0625 & 945706 & & & \\
\hline & 0.125 & 1794720 & & & \\
\hline & 0.25 & 3669585 & & & \\
\hline & 0.5 & 6924286 & & & \\
\hline \multirow[t]{5}{*}{ Glimepiride } & 0.03125 & 1034852 & \multirow{5}{*}{124761} & \multirow{5}{*}{30929176.22} & \multirow{5}{*}{0.9999} \\
\hline & 0.0625 & 2075616 & & & \\
\hline & 0.125 & 3970701 & & & \\
\hline & 0.25 & 7962082 & & & \\
\hline & 05 & 15543192 & & & \\
\hline
\end{tabular}

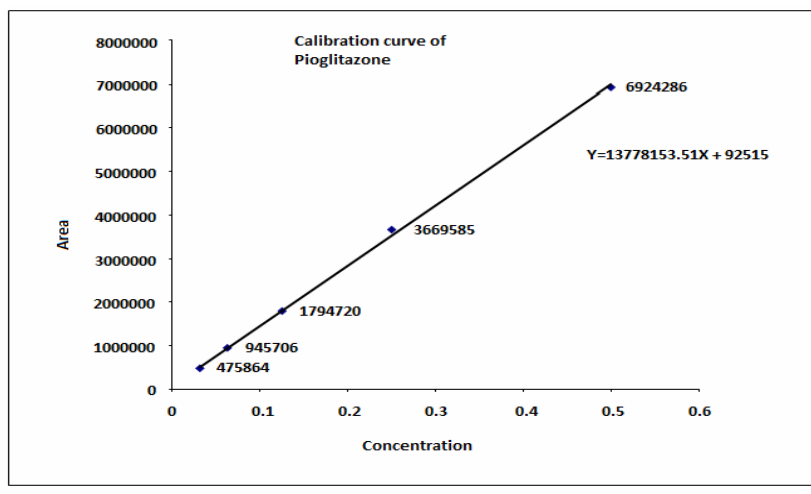

A

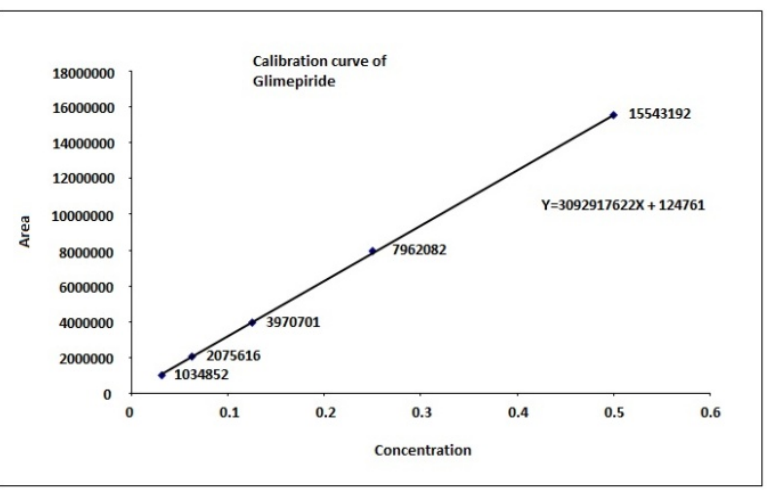

B

Figure 3. Linearity of curve for pioglitazone (A) and glimepiride (B).

The accuracy was evaluated at three different concentrations with spikes which were conducted in successive analysis ( $\mathrm{n}=3$ ) using the proposed method and the value was expressed as percentage of recovery ( $\mathrm{R} \%$ ) between the mean concentrations found and added concentration for both of these drugs. The average percentage of recovery was found to be $99.87 \%, 98.82 \%$, and $99.94 \%$ for $0.05,0.025$ and $0.0125 \mu$ mole/mL, respectively (Table 2).

The precision of proposed method was checked by intra-day and inter-day repeatability of responses after replicate injections of standard solution. The precision of pioglitazone was determined by triplicate injection of $0.05,0.025$ and $0.0125 \mu \mathrm{mole} / \mathrm{ml}$ each day for two 
different days where the mean concentrations were found as $0.050703,0.024927$ and $0.01261 \mu \mathrm{mole} / \mathrm{mL}$ for day-1 associated with RSD\% of $1.0 \%, 0.36 \%$ and $0.28 \%$, respectively; and $0.049895,0.025225$ and 0.01248 $\mu$ mole/mL for day-2 associated with RSD\% of $0.043 \%$, $0.028 \%$ and $0.23 \%$, respectively (Table 3 and 4 ). To determine the precision of glimepiride, the mean concentrations were found as 0.049347, 0.02442 and $0.012533 \mu \mathrm{mole} / \mathrm{ml}$ for day-1 associated with RSD\% of $0.51 \%, 0.78 \%$ and $0.51 \%$, respectively; and 0.04947 , 0.2451 and $0.012535 \mu \mathrm{mole} / \mathrm{ml}$ for day-2 associated with RSD\% of $0.36 \%, 0.29 \%$ and $0.51 \%$, respectively for same concentrations. The RSD\% for intra-day and inter-day assays of pioglitazone and glimepiride in the same laboratory did not exceed more than $2 \%$ (Table 3 and 4 ).
All experimental results were in the range of the acceptable precision and accuracy, which indicate that the newly developed method is sensitive enough and accurate for determination of pioglitazone and glimepiride. Therefore, the method was applied for quantitative and simultaneous analysis of combined pharmaceutical preparation of pioglitazone and glimepiride formulated by local manufacturer. The quantity of active drugs was determined for three marketed preparations (sample-1, sample-2 and sample-3) for each drug and the potency of pioglitazone was found to be $99.94 \%, 101.37 \%$ and 99.79\%, respectively; where as $100.05 \%$, 99.73\% and $100.14 \%$ for glimepiride, respectively (Table 5).

Table 2. Accuracy of the developed method.

\begin{tabular}{cccc}
\hline Drug & $\begin{array}{c}\text { Standard }+ \text { Spike } \\
(\mu \mathrm{mole} / \mathrm{ml})\end{array}$ & $\begin{array}{c}\text { Injected conc. } \\
(\mu \mathrm{mole} / \mathrm{ml})\end{array}$ & Mean recovery (\%) \\
\hline \multirow{3}{*}{ Pioglitazone } & $0.05+0.0$ & 0.05 & 99.885 \\
& $0.025+0.0$ & 0.025 & 98.820 \\
& $0.0125+0.0$ & 0.0125 & 99.940 \\
\hline \multirow{2}{*}{ Glimepiride } & $0.00535+0.5$ & 0.50535 & 99.925 \\
& $0.0002675+0.25$ & 0.250267 & 99.418 \\
& $0.00001338+0.125$ & 0.1250138 & 100.01 \\
\hline
\end{tabular}

Table 3. The intraday precision of the developed method.

\begin{tabular}{lccccccc}
\hline \multirow{2}{*}{ Drug } & Injected & \multicolumn{5}{c}{ Intra-day } \\
\cline { 3 - 8 } & $\begin{array}{c}\text { conc. } \\
(\mu \mathrm{mole} / \mathrm{ml})\end{array}$ & $\begin{array}{c}\text { Mean recovered } \\
\text { conc. }(\mathrm{n}=3) \\
(\mu \mathrm{mole} / \mathrm{ml})\end{array}$ & SD & RSD\% & $\begin{array}{c}\text { Mean recovered } \\
\text { conc. }(\mathrm{n}=3) \\
(\mu \mathrm{mole} / \mathrm{ml})\end{array}$ & SD & RSD\% \\
\hline Pioglitazone & 0.05 & 0.050703 & 0.00051 & 1.0 & 0.049895 & 0.000021 & 0.043 \\
& 0.025 & 0.024927 & 0.00009 & 0.36 & 0.025225 & 0.000007 & 0.028 \\
& 0.0125 & 0.01261 & 0.00004 & 0.28 & 0.01248 & 0.000028 & 0.23 \\
\hline Glimepiride & 0.05 & 0.049347 & 0.00025 & 0.51 & 0.04947 & 0.000184 & 0.36 \\
& 0.025 & 0.02442 & 0.00019 & 0.78 & 0.02451 & 0.000071 & 0.29 \\
& 0.0125 & 0.012533 & 0.00006 & 0.51 & 0.012535 & 0.000064 & 0.51 \\
\hline
\end{tabular}

Table 4. The inter-day precision of the developed method.

\begin{tabular}{lcccc}
\hline Drug & $\begin{array}{c}\text { Injected conc. } \\
(\mu \text { mole/ml })\end{array}$ & $\begin{array}{c}\text { Mean recovered conc. } \\
(\mathrm{n}=3)(\mu \mathrm{mole} / \mathrm{ml})\end{array}$ & $\mathrm{SD}$ & $\mathrm{RSD} \%$ \\
\cline { 3 - 5 } & & 0.050299 & 0.0005716 & 1.14 \\
& 0.05 & 0.025076 & 0.000211 & 0.84 \\
\hline Pioglitazone & 0.025 & 0.012545 & 0.000092 & 0.73 \\
\hline Glimepiride & 0.0125 & 0.049408 & 0.000087 & 0.18 \\
& 0.05 & 0.024465 & 0.000064 & 0.26 \\
& 0.025 & 0.012534 & 0.0000012 & 0.01 \\
\hline
\end{tabular}


Table 5. Sample analysis.

\begin{tabular}{lcccc}
\hline Drug & Sample Code & $\begin{array}{c}\text { Injected conc. } \\
(\mu \mathrm{mole} / \mathrm{mL})\end{array}$ & Mean recovered $(\mu \mathrm{mole} / \mathrm{mL})$ & $\begin{array}{c}\text { Average \% Recovery }=(\mathrm{Mean} \\
\text { recovered conc./ injected conc. }) \times 100\end{array}$ \\
\hline \multirow{3}{*}{ Pioglitazone } & Sample-1 & 0.1 & 0.09994 & 99.94 \\
& Sample-2 & 0.05 & 0.05068 & 101.37 \\
& Sample-3 & 0.025 & 0.02494 & 99.79 \\
\hline \multirow{3}{*}{ Glimepiride } & Sample-1 & 0.0107 & 0.010705 & 100.05 \\
& Sample-2 & 0.00535 & 0.005336 & 99.73 \\
& Sample-3 & 0.00265 & 0.002654 & 100.14 \\
\hline
\end{tabular}

\section{CONCLUSION}

To attain the objective, a rapid and sensitive reversed phase high performance liquid chromatographic method was developed and validated according to the guidelines of FDA, ICH and USP. Since there were good separation and resolution of the chromatographic peaks, the proposed method was found to be simple, precise, accurate, linear, robust and rapid for simultaneous determination and quantification of pioglitazone and glimepiride. The sample recoveries were in good agreement with their respective label claims suggested non-interference in the estimation. Hence, the method can be easily and conveniently adopted for routine analysis of pioglitazone and glimepiride in combined dosage forms.

\section{REFERENCES}

Gillies, P.S. and Dunn, C.J. 2000. Pioglitazone. Drugs 60, 333345.

Smith, U. 2001. Pioglitazone: mechanism of action. Int. J. Clin. Pract. Suppl.121, 13-18.

Belfort, R., Harrison, S.A., Brown, K., Darland, C., Finch, J., Hardies, J., Balas, B., Gastaldelli, A. et al. 2006. A placebocontrolled trial of pioglitazone in subjects with nonalcoholic steatohepatitis. New Engl. J. Med. 355, 2297-2307.

DeFronzo, R.A., Tripathy, D., Schwenke, D.C., Banerji, M.A., Bray, G.A. et al. 2011. Pioglitazone for diabetes prevention in impaired glucose tolerance. New Eng. J. Med. 364, 11041115.

Langtry, H.D., Balfour, J.A. 1998. Glimepiride: a review of its use in the management of type 2 diabetes mellitus. Drugs 55, 563-584.

Rosenkranz, B., Profozic, V., Metelko, Z., Mrzljak, V., Lange, C. and Malerczyk, V. 1996. Pharmacokinetics and safety of glimepiride at clinically effective doses in diabetic patients with renal impairment. Diabetologia 39, 1617-1624.
Müller, G., Satoh, Y. and Geisen, K. 1995. Extrapancreatic effects of sulfonylureas: a comparison between glimepiride and conventional sulfonylureas. Diabet. Res. Clin. Pract. 28 (Suppl. 28), S115-S137.

Sane, R.T., Menon, S.N., Inamdar, S., Mote, M. and Gundi, G. 2004. Simultaneous determination of pioglitazone and glimepiride by high-performance liquid chromatography. Chromatogra. 59, 451-453.

Rezk, M. R., Riad, S. M., Mahmoud G. Y. and Aleem, A.A.E.B.A. 2012. Simultaneous determination of pioglitazone and glimepiride in their pharmaceutical formulations. J. Appl. Pharm. Sci. 2, 177-184.

Kalyankar, T.M., Badgujar, M.R. and Kakde, R.B. 2010. Simultaneous determination of pioglitazone $\mathrm{HCl}$ and glimepiride by RP-HPLC in pharmaceutical dosage form. $J$. Pharm. Res. 3, 3078-3080.

Ramesh, J., Prakasam, A.K.C., Suresh, A., Kumar, A,P. and Anudeep, M. 2010. Simultaneous estimation of pioglitazone $\mathrm{HCl}$ and glimepiride by RP-HPLC method. J. Glob. Trends Pharma. Sci. 1, 68-78.

Lakshmi, K.S., Rajesh, T. and Sharma, S. 2009. Determination of pioglitazone and glimepiride in pharmaceutical formulations and rat plasma by RP-LC. Int. J. PharmTech Res. 1, 496-499.

Karthik, A., Subramanian, G., Rao, M.C., Bhat, K., Ranjithkumar, A., Musmade, P., Surulivelrajan, M., Karthikeyan, K. and Udupa, N. 2008. Simultaneous determination of pioglitazone and glimepiride in bulk drug and pharmaceutical dosage form by RP-HPLC method. Pak. J. Pharm. Sci. 21, 421-425

Sultan, M.Z., Huda, G.Z.U., Hossain, A., Mazid, A. and Rashid, M.A. 2012. Development and validation of a RP-HPLC method for the quantification of sparfloxacin in pharmaceutical dosage forms. Ars Pharm. 53, 11-16.

Sultan, M.Z., Rahman, A.M., Hossain, A. and Rashid, M.A. 2011. Quantification of cephradine in pharmaceutical dosage forms formulated in Bangladesh. J. Dhaka Int. Univ. 3, 121-125. 
Sultan, M.Z., Mazid, M.A. and Rashid, M.A. 2011. Stability assessment of cephradine suspensions formulated in Bangladesh. J. Sci. Res. 3, 383-391.

Food and Drug Administration: Validation and verification guidance for human drug analytical methods (appendix 1), Document No.: ORA-LAB.5.4.5, Version No.: 1.6, pp. 1719, Effective Date: 10-01-03, Revised: 01-25-12; Date of download: 22/10/2012.

Website: http://www.fda.gov/downloads/ScienceResearch/Field Science/UCM092147.pdf
International Conference on Harmonisation (ICH) Harmonised Tripartite Guideline: Text on Validation of Analytical Procedures (Q2A). Website: http://www.ich.org/, Date of download: 22/10/2012.

International Conference on Harmonisation (ICH) Harmonised Tripartite Guideline: Validation of Analytical Procedures: Methodology (Q2B). Website: http://www.ich.org/, Date of download: 22/10/2012.

United States Pharmacopeia (USP 32, NF 27). 2009, section 1225, Validation of compendial methods. 